\title{
FITNESS AND COMFORT ASSESSMENT OF FOOTWEAR: AN ANTHROPOMETRIC APPRAISAL
}

\author{
Adinife Patrick Azodo ${ }^{1 *}$, ORCID ID: 0000-0002-2373-1477, \\ Olasunkanmi Salami Isamaila1,2, ORCID ID: 0000-0002-9875-8594, \\ Sampson Chisa Owhor ${ }^{2}$, ORCID ID: 0000-0003-2126-7903 \\ ${ }^{1}$ Department of Mechanical Engineering, Federal University of Agriculture Abeokuta, Nigeria \\ ${ }^{2}$ Department of Mechanical Engineering, Federal University Wukari, Taraba state, Nigeria \\ *Corresponding author: Adinife Patrick Azodo, azodopat@gmail.com
}

Received: 06. 04. 2021

Accepted: 07. 12. 2021

\begin{abstract}
Suitability determination of any product designed for specific types of consumers is possible through the effective use of anthropometric information. This study assessed anthropometric data utilization in footwear designs and patterns as an indicator of fitness and comfort in footwear production. The data collected for analysis were the length and the breadth dimensions of footwear design pattern from eighteen footwear cottage shops and the foot anthropometric parameter from a total of four hundred and thirty-three (433) (males (226) and females (207)) subjects. The instrumentation design for the data collection was a digital vernier caliper (model Mitutoyo 500-506-10). The analysis of the foot anthropometry dimension and the design footwear pattern data obtained showed a lack of bilateral symmetry for the male and female gender. The fitness and comfortable foot support function of the footwear analyzed using a paired samples t-test between the footwear design pattern dimensions, and the foot anthropometric parameters disclosed $p>0.05$ in all cases - not significant. This study concluded that tailoring a product design to the users' population reduces the mismatch challenges, grants fitness, and comfort to the users.
\end{abstract}

Keywords: foot anthropometry, footwear, fitness, production, cottage firm.

\section{Introduction}

Footwear production, either hand-crafted or produced through the use of high-end machines, follows a sequential and progressive process route, starting with the dimension. The measurement of the size and proportion of the foot parameters for footwear productions is called foot anthropometry. The physical feature of the human foot, in most cases, is the linear dimensions of the foot length and foot breadth [1]. In the developing nation, the footwear fabrication in the cottage sector is with the use of simple tools. The local production in this sector serves the footwear need of a specific population, either on-demand or produced for sales. The basic fundamental in the design and construction of footwear involves quantitative analysis of the physical differences that exist in linear measurements of the foot for comfortable and functional foot support [1]. While walking, running, or 
working, footwear prevents the foot from injuries, offers fitness and comfortable foot support, and protects it against variations of ground surfaces texture and temperature adversities of the environment. It also facilitates the proper functioning of the foot for daily activities [1]. However, this is only guaranteed when the footwear fit with the shape of the foot as it is an essential determinant factor [1]. Beyond the aesthetically pleasing, stylish, and great-looks of footwear, the best choice lies either in the proper foot function or the overall health. Wearing poorly fitting footwear is painful in the ankles, hips, knees, and lower back, and it is debilitating. The aching effect of the feet can zap the energy of a person. Other poorly fitting footwear effects are blisters, bunions, calluses, hammertoes, and blood circulation problems. The foot support offered by the footwear in standing position, walking and accommodation to variations of surfaces can cause change to the skeletal system and the muscular structure that it supports. It can also change a person's posture and the way the person walks if poorly fitted. It then means that for a desired fit and comfort of footwear, foot anthropometry is necessary.

Anthropometric data accommodates a wide range of biological variation of the human body characteristics that uniquely distinguishes individuals [2, 3]. The diversity in anthropometric of the human body characteristics cut across age, gender, tribe, geographical location, occupation, and nationality [4]. The defining factors that make for the classification and identification of the physical geometry of the human body of a group are cover in the body anthropometry. It guides in the development and establishment of the standards that are specific for effective product design, and enhance product usability and suitability for the user population $[5,6,7]$. Studies revealed that the development of standard anthropometric data helps to solve the significant variations of the human body dimensions through the provision of vital database information applicable to the design of products [8]. Ismaila [3] emphasized that for product design to suit specific types of consumers, anthropometry data is needed as it varies from person to person and between nations. In practice, garment makers, clothes, and footwear measure their customers to design the wears that fit the individuals. Garment production for easy and short time accessibility, as well as the relatively inexpensive products, requires consultation of anthropometry database. This phenomenon has a significant effect on the development of garment industries. Anthropometry positively affects the desired economies of scale conditions in the development of product design sector. Also, it reduces setup-time and stoppages in the mass production of readymade products [8].

The understanding of the importance of anthropometry values, according to Musa et al. [9], lies in its application. This is because an individual's body anthropometry for fitness and comfortable garment needs to capture the variations as the human foot shows a range of variation in length, breadth, and height due to genetic, natural, and environmental factors [10]. The challenge with the user population and the anthropometric data for Nigerians is in the sparse nature, mostly found from individual researchers and skewed to a particular state, region, gender, age, or ethnicity $[3,11]$. Tackling these ranges of variations in the human body anthropometry by accommodating to the extreme deviation to the 5th and 95th percentiles of a population across age, gender, tribe, and nationality gives a significant suitability determination of a product targeted for a particular people [5, 12, 13]. Most foot anthropometry research studies found in the works of literature covered foot shape under different weight-bearing conditions [1, 14], and foot dimensions evaluation [3, 15]. Similar studies such as $[16,17,18]$, considered gender and tribe. In other studies, anthropometry of 
the foot was used in the estimation of the body standing height [19, 20, 21]. Monye and Omotehinse [22] developed a model of foot anthropometric descriptors for the design of prosthesis and footwear in Nigeria. Likewise, Nacher et al. [23] developed a model for predicting footwear fit based on user data. However, the application of anthropometry data for the design for a target user's population as guidelines for designers of commercial products, necessary for product usability and suitability for the user population, is still scarce. Therefore, this study assessed the anthropometry of footwear designs and patterns as an indicator of fitness and comfort for sandals and chappals production.

\section{Materials and method}

This study was conducted in the Ukum local government area of Benue state Nigeria with study site locations at Jootar and Zarki-ibaim areas. The data sampling of this study covered the physical measurement of the footwear design patterns used in eighteen (18) footwear making shops. The sampled footwear making shops were those that locally design the straps and the soles of the footwear for sale. The foot anthropometric data measurements were from a total of four hundred and thirty-three (433) participants, males (226) and females (207) contacted at the footwear making shops. The footwear design pattern dimensions (Figure 1) and the foot anthropometric parameter (Figure 2) measurements were the foot length and the foot breadth dimensions using a digital vernier caliper (model Mitutoyo 500506-10, Mitutoyo Corporation, Japan).

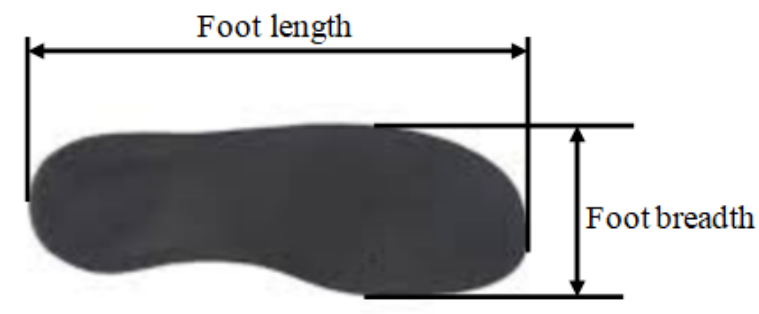

Figure 1. Footwear design pattern dimensions.

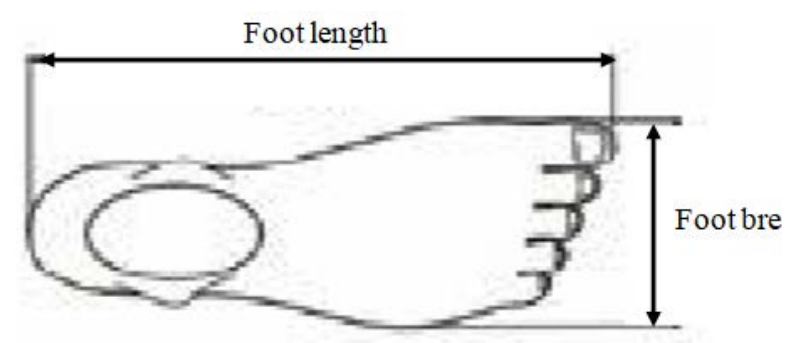

Figure 2. Foot anthropometric parameter.

As this study is a forensic study, the measurement precision and reliability were ensured as only one of the researchers did the data collection. The foot lengths and foot breadths measurements were carried out when the participant is in a seated position barefooted with the foot flat on the ground making an angle ninety degrees at the talocrural (ankle) joint. Foot breadth measurement is the distance across the metatarsal region of the foot from the lateral to the medial side. Foot length measured the maximum distance between the most anterior part of the heel and the posterior projecting end of the foot. The measurements on the footwear design pattern were the corresponding positions and dimensions for the foot lengths and foot breadths for each of the participants' foot anthropometry. The subjects agreed to participate in this study verbally. The recruitment was after an explanation of the purpose of the study was communicated to the participants. Data analyzed was only from those who gave their permission and with no physical deformities on their feet. The data obtained were descriptive and inferential statistical analyses. The comparison of the foot anthropometric data of the subjects and design footwear pattern for the significant difference was with the use a 2-tailed paired samples t-test on the SPSS 20.0 Statistical package. The value considered for the significant difference between the foot anthropometric data and footwear design pattern is less than 0.05 . 


\section{Results and Discussions}

Table 1 shows the descriptive statistics of the foot anthropometry variables for the males and the female genders. From the table, the average mean value for the right foot length $(27.45 \mathrm{~cm})$ and the right foot breadth $(10.17 \mathrm{~cm})$ were longer than the left foot length $(27.44 \mathrm{~cm})$ and the left foot breadth $(10.16 \mathrm{~cm})$ (Table 1). For the female participants, the average mean value for the right foot length $(25.29 \mathrm{~cm})$ was higher than the left foot length $(25.28 \mathrm{~cm})$. The average mean value of right foot breadth $(8.83 \mathrm{~cm})$ is lower than the right foot breadth $(8.85 \mathrm{~cm}$ ) (Table 1). This study observed a lack of bilateral symmetry in both the foot anthropometry dimension of the participants for both the male and female gender. The lack of bilateral symmetry in the foot anthropometry dimension for both gender found in this study in line with observation in previous similar studies [24-29].

Table 1

\section{Descriptive statistics of foot anthropometry dimension for gender}

Descriptive Male $=226 \quad$ Female $=207$

statistics

\begin{tabular}{lllllllll} 
& Right & & Right & \multicolumn{3}{c}{ Right } & \multicolumn{3}{c}{ Right } \\
& FT & Left FT & FB & Left FB & FT & Left FT & FB & Left FB \\
\hline Min $(\mathrm{cm})$ & 24.04 & 24.11 & 9.00 & 9.01 & 22.23 & 22.00 & 8.04 & 8.04 \\
Max (cm) & 30.00 & 29.98 & 11.78 & 11.43 & 28.44 & 28.96 & 9.98 & 10.02 \\
Mean (cm) & 27.45 & 27.44 & 10.17 & 10.16 & 25.29 & 25.28 & 8.83 & 8.85 \\
SD (cm) & 1.68 & 1.69 & 0.55 & 0.56 & 1.08 & 1.15 & 0.52 & 0.54 \\
\hline
\end{tabular}

The design footwear pattern used in the cottage firm for the sandals and chappals footwear production followed a different order (Table 2). The measured dimension of the design footwear pattern used in the cottage firm for the female subjects' footwear production showed that average the right foot length and left foot length are of the same dimension $(25.15 \mathrm{~cm})$. The foot breadths have variation as the left foot breadth $(8.88 \mathrm{~cm})$ was found higher than the right foot breadth $(8.86 \mathrm{~cm})$ (Table 2). The design footwear pattern also observed a lack of bilateral symmetry in the male and female design footwear pattern. The variation in the footwear design dimension implies that both sides of the pairs are not equal.

Table 2

Descriptive statistics of footwear pattern dimension for gender

\begin{tabular}{lllllllll}
\hline $\begin{array}{l}\text { Descriptive } \\
\text { statistics }\end{array}$ & \multicolumn{4}{c}{ Male $=226$} & & \multicolumn{5}{c}{ Female $=207$} \\
& \cline { 2 - 9 } & Right & \multicolumn{3}{c}{ Right } & \multicolumn{3}{c}{ Right } \\
& FT & Left FT & FB & Left FB & FT & Left FT & FB & Left FB \\
\hline Min (cm) & 24.7 & 24.9 & 9.43 & 9.45 & 22.7 & 22.5 & 8.18 & 8.52 \\
Max (cm) & 29.4 & 29.6 & 11 & 10.9 & 27.9 & 28.1 & 9.64 & 9.54 \\
Mean (cm) & 27.3 & 27.28 & 10.22 & 10.16 & 25.15 & 25.15 & 8.86 & 8.88 \\
SD (cm) & 1.58 & 1.53 & 0.38 & 0.38 & 1.05 & 1.14 & 0.38 & 0.32 \\
\hline
\end{tabular}

Table 3 compares the average mean of the foot anthropometry variables with the corresponding variable on the design footwear pattern dimension for both genders. The result obtained showed that for the males, the average mean value of the right foot length anthropometry parameter had a higher mean value $(27.45(S D=1.68)$ compared to the right foot length of the design footwear pattern parameter that had $27.30(S D=1.58), t(225)=-$ 
$1.07, p=0.28$ (Table 3 ). The result obtained means that the right foot length anthropometry variables and the corresponding right foot length of the design footwear pattern dimension were not significantly different as the $p$-value was higher than 0.05 . The high $p$-value obtained from the paired $t$-test indicated that the design footwear pattern parameters used for the right foot length anthropometry parameter for the male subjects gave the desired fits. Similarly, the paired samples t-test for the left foot length $(p=0.27)$, right foot breadth ( $p=$ $0.25)$, and left foot breadth $(p=0.89)$ between the foot anthropometry and design footwear pattern were not significantly different as the values were higher than 0.05 (Table 3). The result obtained implies that the basis adopted for designing footwear at the cottage firm assessed gave the desired fit need for comfort. This study established that guided anthropometry developed and used at the cottage firms for the footwear design and production in this study matched the studied population fitness and comfort. This finding is in agreement with the postulations in several other similar studies [5 - 7].

Table 3

Paired sample t-test for the foot anthropometry variables and design footwear pattern dimension for the male subjects

\begin{tabular}{llllllll}
\hline \multirow{2}{*}{ Anthropometry variables } & \multicolumn{5}{c}{ Descriptive statistics } & t-test for equality of means \\
\cline { 3 - 8 } & Mean & SD & SEM & t & Df & p-value \\
\hline Right FT & Foot anthropometry variables & 27.45 & 1.68 & 0.11 & & & \\
& Design footwear pattern & 27.30 & 1.58 & 0.11 & 1.07 & 225 & 0.28 \\
\multirow{2}{*}{ Left FT } & Foot anthropometry variables & 27.44 & 1.69 & 0.11 & & & \\
& Design footwear pattern & 27.28 & 1.53 & 0.1 & 1.1 & 225 & 0.27 \\
\multirow{2}{*}{ Right FB } & Foot anthropometry variables & 10.17 & 0.55 & 0.04 & & & \\
& Design footwear pattern & 10.22 & 0.38 & 0.03 & -1.16 & 225 & 0.25 \\
\multirow{2}{*}{ Left FB } & Foot anthropometry variables & 10.16 & 0.56 & 0.04 & & & \\
& Design footwear pattern & 10.16 & 0.38 & 0.03 & -0.14 & 225 & 0.89 \\
\hline
\end{tabular}

Table 4 shows the comparison of the average mean of the foot anthropometry parameters and the foot design pattern for the female participants. The paired samples t-test comparison made between the foot anthropometry parameters and the foot design pattern for the foot length and foot breadth on both legs showed that there was a significant difference in all cases.

The $p$-value obtained for each was higher than 0.05 .

The result obtained demonstrated that the foot anthropometry data used in the cottage shops is suitable for the study population.

This study also showed that the product design specific to a group of people helped in the achievement of footwear fitness and comfort. Therefore, the finding in this study buttressed Cooper et al. [30] statement that the anthropometry data must be appropriate to the design of a product and must be descriptive to the target users' population for the product design to be effective. As such, it forms the guidelines for footwear designers for the commercial production of footwear. 
Table 4

Paired sample t-test for the foot anthropometry variables and design footwear pattern dimension for the female subjects

\begin{tabular}{|c|c|c|c|c|c|c|c|}
\hline \multicolumn{2}{|c|}{ Anthropometry variables } & \multicolumn{3}{|c|}{ Descriptive statistics } & \multicolumn{3}{|c|}{ t-test for equality of means } \\
\hline & & Mean & SD & SEM & $\mathrm{T}$ & Df & p-value \\
\hline \multirow[t]{2}{*}{ Right FT } & Foot anthropometry variables & 25.29 & 1.08 & 0.07 & & & \\
\hline & Design footwear pattern & 25.15 & 1.05 & 0.07 & 1.64 & 206 & 0.10 \\
\hline \multirow[t]{2}{*}{ Left FT } & Foot anthropometry variables & 25.28 & 1.15 & 0.08 & & & \\
\hline & Design footwear pattern & 25.15 & 1.14 & 0.08 & 1.40 & 206 & 0.16 \\
\hline \multirow[t]{2}{*}{ Right FB } & Foot anthropometry variables & 8.83 & 0.52 & 0.04 & & & \\
\hline & Design footwear pattern & 8.86 & 0.38 & 0.03 & -0.84 & 206 & 0.40 \\
\hline \multirow[t]{2}{*}{ Left FB } & Foot anthropometry variables & 8.85 & 0.54 & 0.04 & & & \\
\hline & Design footwear pattern & 8.88 & 0.32 & 0.02 & -0.83 & 206 & 0.41 \\
\hline
\end{tabular}

\section{Conclusion}

The anthropometry assessment of the human body or any part of the human body through physical measurements is a means of identification of the body characteristics. This physical measurement exposes any deformities or impaired integrity and provides useful information on the measured part. The fitness of the footwear design pattern used in the production of footwear in the cottage firms in Nigeria assessed in this study showed that there no significant difference between the foot anthropometry variables and footwear design pattern dimension for the male and the female gender. This study has demonstrated that tailoring a product design to the users' population reduces the mismatch challenges, grant fitness, and comfort to the users. However, this study only covered two-foot anthropometry variables, foot length and foot breadth, applicable in sandals and chappals production. Further studies are recommended that will consider other parameters of the foot anthropometry. As well data collection should be extended to more population and classified according to ages.

\section{References}

1. Oladipo G., Bob-Manuel I., Ezenatein G. Quantitative comparison of foot anthropometry under different weight bearing conditions amongst Nigerians. In: The Internet Journal of Biological Anthropology, 2008, 3(1).

2. Osunwoke E.A., Vidona W.B., Atulegwu G.C. Anthropometric study on the anatomical variation of the external ear amongst Port Harcourt students, Nigeria. In: International Journal of Anatomical Variations, 2018, 11(4), pp. $143-146$.

3. Ismaila S.O. Anthropometric data of hand, foot and ear of university students in Nigeria. In: Leonardo Journal of Sciences, 2009, 15(8), pp. 15 - 20

4. Kaankuka T.K. Ikyaator, M.T. Umogbai V.I. Development of anthropometric data for Benue state Nigeria agricultural workers. In: International Journal of Engineering and Technology, 2016, 6(8), pp. 271 - 276.

5. Agrawal K.N., Singh R.K.P., Satapathy K.K. Anthropometric considerations of farm tools/machinery design for tribal workers of Northeastern India. In: Agricultural Engineering International: CIGR Journal, 2010, 12(1), pp. $143-150$.

6. Caragliu B. Fitness for drivers. In: Italian Journal of Occupational Medicine and Ergonomics, 2006, 28 (1), pp. 82-84.

7. Muzammil M., Rizvi S., Hassan F. Hassan S.N. Anthropometric data with special reference to the indian needsan overview. In: Journal of the Institution of Engineers (India) Part PR, Production Engineering Division, 2007, 87, pp. 14 - 19. 
8. Beshah B., Belay B., Tilahun S., Tizazu B., Matebu A. Anthropometric data of Bahirdar City's adult men for clothing design. In: International Journal of Vocational and Technical Education, 2014, 6(1), pp. 51 - 57.

9. Musa A., Ismaila S., Adejuyigbe S., Akinyemi O. Abolarin M. Comparison of biomechanical and anthropometrical data of Nigeria tertiary institution students with some selected countries. In: Management Science Letters, 2012, 2(6), pp. 1885 - 1894.

10. Amitava P., Sujaya D., Piyali S., Payel M., Prakash C.D. Estimation of stature from hand dimensions in Bengalee population, West Bengal, India. In: Egyptian Journal of Forensic Sciences, 2016, 6(2), pp. 90 - 98.

11. Muhammad A.U., Abdullah K.A., Faris W.F. Automotive seat fit parameters based on representative Nigerian anthropometric data. In: Malaysian Journal of Public Health Medicine, 2018, 2, pp. 32 - 40.

12. Ismaila S.O., Akanbi O.G., Adekunle N.O., Adetunji O.R., \& Kuyue S.I. An ergonomics assessment of passenger seats in buses in South Western Nigeria. In: Sigurnost: časopis za sigurnost u radnoj i životnoj okolini, 2010, 52(4), pp. 329-334.

13. Ashby P. Ergonomics handbook 1: Human factors design data: Body size and strength. Pretoria: Tute Publication. 1978

14. Tsung B.Y.S. Quantitative comparison of planter foot shapes under different weight bearing conditions. In: Journal of Rehabilitation Research \& Development, 2003, 40(6), pp. 517 - 526.

15. Obikili E.N., Didia B.C. Foot dimensions of a young adult Nigerian population. In: Anatomical Society of Eastern Nigeria, 2006, 1, pp. 22 - 24.

16. Danboro B., Elukpo A. Sexual dimorphism in hand and foot length, indices, stature ratio and relationship to height in Nigerians. In: Forensic Science International - Journal, 2008, 3(1), pp. 1-5.

17. Reena S., Minu B., Mrinal B. Sex estimation from foot anthropometry in Haryanvijats and North Indian mixed population. In: Journal of Punjab Academy of Forensic Medicine \& Toxicology, 2012, 12 (1), 13-16.

18. Ekezie J. Foot Anthropometry; A forensic and prosthetic application. In: International Journal of Science and Research (IJSR), 2013, 4(6), 738 - 746

19. Ozden H., Balci Y., Demirüstü C., Turgut A., Ozden E.M. Stature and sex estimate using foot and shoe dimensions. In: Forensic Science International - Journal, 2005, 147(2 - 3), pp. 181 -184

20.Jitender K.J. Estimation of height from measurement of foot length in Haryana region. In: Journal of Indian Academy of Forensic Medicine. 2010, 32(3), pp. 231 - 233.

21. Sonali K., Ashish R. Estimation of stature from the measurement of foot length, hand length and head length in Maharashtra region. In: Indian Journal of Basic and Applied Medical Research, 2012, 2(1), pp. 77 - 85.

22. Monye I.S., Omotehinse S.A. Developing a model for foot anthropometric descriptors for the design of prosthesis and footwear in Nigeria. In: Journal of Applied Sciences and Environmental Management, 2019, 23(12), pp. 2165-2170.

23. Nacher B., Alemany S., Gonzalez J.C., Alcantara E., Garcia J., Hernanadez S., Heras Juan A. A footwear fit classification model based on Anthropometric Data. DHM. 2006, pp. 01 - 2356.

24. Igbigbi P.S., Ominde B.S., Adibeli C.F. Anthropometric dimensions of hand and foot as predictors of stature: A study of two ethnic groups in Nigeria. In: Alexandria Journal of Medicine, 2018, 54(4), pp. $611-617$.

25. Nirenberg M.S., Krishan K., Kanchan T. A metric study of insole foot impressions in footwear of identical twins. In: Journal of Forensic and Legal Medicine. 2017, 52, pp. 116 - 121.

26. Saka O. S., Alamu O.A., Olayode A.A., Akinjisola A.A., Ogundipe J.O. Studies on the estimation of stature from hand and foot length of an individual. In: Journal of Krishna Institute of Medical Sciences University, 2016, 5, pp. $73-80$.

27. Kanchan T., Sinha S., Krishan K. Is there a correlation between footstep length, lower extremities, and stature? In: Journal of Forensic Sciences, 2015, 60(5), pp. 1337 - 1340.

28. Ishak N.I., Hemy N., Franklin D. Estimation of stature from hand and handprint dimensions in a Western Australian population. In: Forensic Science International, 2012, 216, pp. 1 - 3.

29. Krishan K., Kanchan T., Menezes R.G. Ghosh A. Forensic anthropology case work essential methodological considerations in stature estimation. In: Journal of Forensic Nursing, 2012, 8, pp. 45 - 50. 10.1111/j. 19393938. 2011.01122. x Epub 2012 ja.

30. Cooper R.A. Bedi J., Gross F. Mechanical efficiency of training wheelchair racers. In: the Proceedings of the 11th Annual IEEE-EMBS Conference, Philadelphia PA: IEEE-Press, 1990, 12(5), pp. 2311 - 2312. 